University of Nebraska - Lincoln

DigitalCommons@University of Nebraska - Lincoln

Faculty Papers and Publications in Animal

Science

Animal Science Department

January 1999

\title{
Estimation of Direct, Maternal, and Grandmaternal Genetic Effects for Weaning Weight in Several Breeds of Beef Cattle
}

\author{
J. Dodenhoff \\ University of Nebraska-Lincoln \\ L. Dale Van Vleck \\ University of Nebraska-Lincoln, dvan-vleck1@unl.edu \\ K. E. Gregory \\ Roman L. Hruska U.S. Meat Animal Research Center, USDA-ARS
}

Follow this and additional works at: https://digitalcommons.unl.edu/animalscifacpub

Part of the Animal Sciences Commons

Dodenhoff, J.; Van Vleck, L. Dale; and Gregory, K. E., "Estimation of Direct, Maternal, and Grandmaternal Genetic Effects for Weaning Weight in Several Breeds of Beef Cattle" (1999). Faculty Papers and Publications in Animal Science. 279.

https://digitalcommons.unl.edu/animalscifacpub/279

This Article is brought to you for free and open access by the Animal Science Department at DigitalCommons@University of Nebraska - Lincoln. It has been accepted for inclusion in Faculty Papers and Publications in Animal Science by an authorized administrator of DigitalCommons@University of Nebraska - Lincoln. 


\title{
Estimation of Direct, Maternal, and Grandmaternal Genetic Effects for Weaning Weight in Several Breeds of Beef Cattle ${ }^{1}$
}

\author{
J. Dodenhoff*,2, L. D. Van Vleckt,3, and K. E. Gregory
}

*Department of Animal Science, University of Nebraska, Lincoln 68583-0908 and Roman L. Hruska U.S. Meat Animal Research Center, ARS, USDA, †Lincoln and $\neq_{C}$ Clay Center, NE 68933

\begin{abstract}
Weaning weights from nine parental breeds and three composites were analyzed to estimate variance due to grandmaternal genetic effects and to compare estimates for variance due to maternal genetic effects from two different models. Number of observations ranged from 794 to 3,465 per population. Number of animals in the pedigree file ranged from 1,244 to 4,326 per population. Two single-trait animal models were used to obtain estimates of covariance components by REML using an average information method. Model 1 included random direct and maternal genetic, permanent maternal environmental, and residual environmental effects as well as fixed sex $x$ year and age of dam effects. Model 2 in addition included random grandmaternal genetic and permanent grandmaternal environmental effects to account for maternal effects of a cow on her daughter's maternal ability. Non-zero estimates of proportion of variance due to grandmaternal effects were obtained
\end{abstract}

for 7 of the 12 populations and ranged from .03 to .06 . Direct heritability estimates in these populations were similar with both models. Existence of variance due to grandmaternal effects did not affect the estimates of maternal heritability $\left(\mathrm{m}^{2}\right)$ or the correlation between direct and maternal genetic effects $\left(r_{\mathrm{am}}\right)$ for Angus and Gelbvieh. For the other five populations, magnitude of estimates increased for both $\mathrm{m}^{2}$ and $\mathrm{r}_{\mathrm{am}}$ when estimates of variance due to grandmaternal effects were not zero. Estimates of the correlation between maternal and grandmaternal genetic effects were large and negative. These results suggest that grandmaternal effects exist in some populations, that when such effects are ignored in analyses maternal heritability may be underestimated, and that the correlation between direct and maternal genetic effects may be biased downward if grandmaternal effects are not included in the model for weaning weight of beef cattle.

Key Words: Beef Cattle, Growth, Genetic Parameters

(01999 American Society of Animal Science All rights reserved.

J. Anim. Sci. 1999. 77:840-845

\section{Introduction}

Animal models used to analyze maternally influenced traits of beef cattle (e.g., birth and weaning weights) typically include direct and maternal effects and a permanent environmental effect of the dam (e.g., Meyer, 1992b; Waldron et al., 1993; Robinson, 1996a). This model was originally proposed by Willham (1963), but, it is actually used in a "reduced"

\footnotetext{
${ }^{1}$ Published as paper no. 12228, J ournal Ser., Nebraska Agric. Res. Div., Univ. of Nebraska, Lincoln 68583-0908. Support of the senior author by the German Research Foundation (DFG) is acknowledged.

${ }^{2}$ Current address: Bayerische Landesanstalt fuer Tierzucht, 85586 Grub, Germany.

${ }^{3}$ To whom correspondence should be addressed: A218 Animal Sciences, Univ. of Nebraska, Lincoln 68583-0908 (phone: 402/ 472-6010; fax: 402/472-6362).

Received April 24, 1998.

Accepted September 20, 1998.
}

form because the environmental dam-offspring covariance is assumed to be zero (Koerhuis and Thompson, 1997). Thompson (1976) and Meyer (1992a) described the difficulties of estimating all of the parameters in Willham's model. The assumption of a zero environmental dam-offspring covariance may result in a more accurate estimate of the remaining variance components, but the failure to account for a non-zero environmental covariance between dam and offspring may bias the estimates of the correlation between the direct and the maternal genetic effects (Koerhuis and Thompson, 1997). This correlation, which is often estimated to be negative (see Meyer, 1992b), may be biased downward due to a negative influence of dams on their daughters' maternal ability through overfeeding (e.g., Koch, 1972; Willham, 1972; Baker, 1980; Cantet et al., 1988). Concern that estimates of the correlation between direct and maternal genetic effects might be biased is also expressed in National Cattle Evaluation programs; 6 
of 12 breed associations assume this correlation to be zero (BIF, 1996).

Willham (1972) extended his model to include grandmaternal effects (i.e., the influence of the maternal granddam phenotype on the dam's maternal effect). Such a model was used to estimate maternal and grandmaternal effects for birth and weaning weights in Hereford cattle (Dodenhoff et al., 1998a); grandmaternal effects were found to be important for weaning weight.

Our objectives were to estimate grandmaternal genetic effects for weaning weight in different breeds and to compare estimates of maternal genetic effects from models including or not including grandmaternal effects.

\section{Materials and Methods}

Data for this analysis were from the U.S. Meat Animal Research Center (USMARC) at Clay Center, NE where nine parental breeds and three composites were used to analyze breed effects and heterosis retention in composite populations of beef cattle. Details on how the parental breed populations were established and how they were mated to create the composites can be found in Gregory et al. (1991). The parental breeds either were maintained as closed breeding populations, came from upgrading programs, or were mated to establish the composites: MARC I (1/ 4 Braunvieh, 1/4 Charolais, 1/4 Limousin, 1/8 Angus, and 1/8 Hereford), MARC II (1/4 Gelbvieh, 1/4 Simmental, $1 / 4$ Angus, and $1 / 4$ Hereford), and MARC III (1/4 Pinzgauer, 1/4 Red Poll, 1/4 Angus, and 1/4 Hereford). Weaning weight records adjusted to $200 \mathrm{~d}$ were from calves born from 1978 through 1992 (Pinzgauer started in 1982, MARC III in 1980). Pedigree information from parents without records was added. Average 200-d weaning weights and numbers of records, sires, dams, granddams, and animals in the relationship matrix are given in Table 1.

Each population was analyzed separately with two single-trait animal models. Fixed effects fitted in both models were sex $\times$ year combination and age of dam, where age of dam had four levels $(2,3,4$, and $5 \mathrm{yr}$ and older). Model 1 was Willham's (1963) basic model, but the covariance between permanent environmental effects of the dam and error effects was assumed to be zero:

$$
\mathbf{y}=\mathbf{X b}+\mathbf{Z}_{1} \mathbf{a}+\mathbf{Z}_{2} \mathbf{m}+\mathbf{W}_{1} \mathbf{p}+\mathbf{e}
$$

Model 2 was based on Model 1 and was extended to include grandmaternal effects:

$$
\mathbf{y}=\mathbf{X b}+\mathbf{Z}_{1} \mathbf{a}+\mathbf{Z}_{2} \mathbf{m}+\mathbf{Z}_{3} \mathbf{g}+\mathbf{W}_{1} \mathbf{p}+\mathbf{W}_{2} \mathbf{q}+\mathbf{e}
$$

where $\mathbf{y}$ is a $\mathbf{N} \times 1$ vector of observations; $\mathbf{b}$ is the vector of fixed effects; $\mathbf{a}, \mathbf{m}$, and $\mathbf{g}$ are vectors of breeding values for direct genetic, maternal genetic, and grandmaternal genetic effects; $\mathbf{p}$ and $\mathbf{q}$ are vectors of permanent maternal environmental and permanent grandmaternal environmental effects; $\mathbf{e}$ is the vector of random error effects; and $\mathbf{X}, \mathbf{Z}_{1}, \mathbf{Z}_{2}, \mathbf{Z}_{3}, \mathbf{W}_{1}$, and $\mathbf{W}_{2}$ are known incidence matrices relating observations to their respective fixed and random effects. Matrices $\mathbf{Z}_{1}$, $\mathbf{Z}_{2}$, and $\mathbf{Z}_{3}$ were augmented for animals without records that were included in the relationship matrix. For both models,

$$
\mathrm{E}[\mathbf{y}]=\mathbf{X b} .
$$

The (co)variance structure of the random effects for Model 2 was as follows:

$$
\mathrm{V}\left[\begin{array}{l}
\mathbf{a} \\
\mathbf{m} \\
\mathbf{g} \\
\mathbf{p} \\
\mathbf{q} \\
\mathbf{e}
\end{array}\right]=\mathrm{V}=\left[\begin{array}{llllll}
\mathbf{A} \sigma_{\mathrm{a}}^{2} & \mathbf{A} \sigma_{\mathrm{am}} & \mathbf{A} \sigma_{\mathrm{ag}} & 0 & 0 & 0 \\
\mathbf{A} \sigma_{\mathrm{am}} & \mathbf{A} \sigma_{\mathrm{m}}^{2} & \mathbf{A} \sigma_{\mathrm{gm}} & 0 & 0 & 0 \\
\mathbf{A} \sigma_{\mathrm{ag}} & \mathbf{A} \sigma_{\mathrm{gm}} & \mathbf{A} \sigma_{\mathrm{g}}^{2} & 0 & 0 & 0 \\
0 & 0 & 0 & \mathbf{I}_{\mathrm{N}_{\mathrm{d}}} \sigma_{\mathrm{p}}^{2} & 0 & 0 \\
0 & 0 & 0 & 0 & \mathbf{I}_{\mathrm{N}_{\mathrm{g}}} \sigma_{\mathrm{q}}^{2} & 0 \\
0 & 0 & 0 & 0 & 0 & \mathbf{I}_{\mathrm{N}} \sigma_{\mathrm{e}}^{2}
\end{array}\right]
$$

where $\mathrm{N}_{\mathrm{d}}$ and $\mathrm{N}_{\mathrm{g}}$ are numbers of dams and grandams, respectively, and $\mathrm{N}$ is number of records; $\mathbf{A}$ is the numerator relationship matrix among animals in the pedigree file, and the I matrices are identity matrices. Covariances between maternal and grandmaternal permanent environmental effects as well as covariances between permanent environmental and residual effects were assumed to be zero. Let $\mathbf{Z}=\left[\mathbf{Z}_{1}\left|\mathbf{Z}_{2}\right| \mathbf{Z}_{3}\right]$, $\mathbf{W}=\left[\mathbf{W}_{1} \mid \mathbf{W}_{2}\right], \mathbf{u}^{\prime}=\left[\mathbf{a}^{\prime}\left|\mathbf{m}^{\prime}\right| \mathbf{g}^{\prime}\right], \mathbf{c}^{\prime}=\left[\mathbf{p}^{\prime} \mid \mathbf{q}^{\prime}\right], \mathbf{V}(\mathbf{u})=\mathbf{G}$, $\mathbf{V}(\mathbf{c})=\mathbf{Q}$ and $\mathbf{V}(\mathbf{e})=\mathbf{R}$ so that $\mathbf{V}(\mathbf{y})=\mathbf{V}=\mathbf{Z} \mathbf{G} \mathbf{Z}^{\prime}+$ WQW $+\mathbf{R}$.

Extending Model 1 to include grandmaternal effects is similar to extending a simple animal model with only direct and residual effects to include maternal effects. In that case, the residual effect is partitioned into a temporary environmental effect (of the calf) and a maternal effect that consists of a genetic effect (maternal genetic effect), a permanent environmental effect, and a temporary environmental effect. To include grandmaternal effects, the temporary environmental effect of the maternal effects model is partitioned into a temporary environmental effect (of the dam) and a maternal effect that again has a genetic effect (grandmaternal genetic effect), a permanent environmental effect (of the granddam), and a temporary environmental effect. The extended model has three genetic effects, two permanent environmental effects, and three temporary environmental effects, which are combined as a residual effect. When Willham (1972) defined a model to include grand- 
Table 1. Characteristics of the data by breed

\begin{tabular}{lccrrrr}
\hline \hline & Weaning & \multicolumn{5}{c}{ Number } \\
\cline { 3 - 7 } & weight, $\mathrm{kg}$ & Records & Sires & Dams & Granddams & Animals \\
\hline Angus & 194.7 & 1,911 & 82 & 842 & 607 & 2,755 \\
Braunvieh & 243.1 & 1,321 & 62 & 560 & 390 & 1,832 \\
Charolais & 234.2 & 1,336 & 59 & 544 & 386 & 1,887 \\
Gelbvieh & 245.9 & 1,174 & 55 & 429 & 301 & 1,629 \\
Hereford & 183.8 & 1,395 & 69 & 571 & 449 & 2,143 \\
Limousin & 209.8 & 1,409 & 58 & 541 & 379 & 1,946 \\
Pinzgauer & 239.0 & 794 & 42 & 344 & 261 & 1,244 \\
Red Poll & 209.5 & 1,300 & 54 & 559 & 380 & 1,744 \\
Simmental & 243.9 & 1,302 & 69 & 581 & 424 & 1,995 \\
MARC I & 237.5 & 2,806 & 120 & 970 & 597 & 3,625 \\
MARC II & 239.6 & 3,465 & 117 & 1,058 & 710 & 4,326 \\
MARC III & 224.2 & 2,478 & 91 & 879 & 611 & 3,212 \\
\hline
\end{tabular}

maternal effects he did not separate maternal and grandmaternal permanent environmental effects. Willham (1972) also noted that all the previous dams in the pedigree could be involved in influencing the maternal effects, but he stopped at this point to keep the covariances as simple as possible.

Variance and covariance components were estimated by REML using an average information algorithm ( AI RE ML) (J ohnson and Thompson, 1995). The AI REML algorithm is a quasi-Newton algorithm that uses first derivatives of the logarithm of the likelihood ( $\mathbf{L}$ ) and an average of observed and expected second derivatives to find estimates of genetic parameters that maximize $L$. The inverse of the coefficient matrix needed to calculate first derivatives of the likelihood was obtained using sparse matrix algorithms described by Takahashi et al. (1973) and implemented in FSPAK (Perez-Enciso et al., 1992). Convergence was assumed to have been reached if the Euclidian norm of the vector of first derivatives was less than $10^{-4}$.

Standard errors of the estimated variance components, heritabilities, and correlations were derived from the inverse of the negative average information matrix considering it to be an asymptotic dispersion matrix of the estimated parameters (i.e., $\vee(\hat{\theta})=$ $\left[-\mathrm{Al}^{-1}\right)$. A Taylor series expansion was used to estimate variances of functions of random variables (e.g., Stuart and Ord, 1994). See Dodenhoff et al. (1998a) for details.

A likelihood ratio test (e.g., Dobson, 1990) was used to compare Models 1 and 2. The difference between the $-2 \mathrm{~L}$ values from the two models was assumed to be distributed as $\chi^{2}$ with four degrees of freedom. Model 2 would seem to have five (co)variances more than Model 1 , but the covariance between the permanent environmental effects had to be assumed to be zero. Critical values for significance were $9.49(\mathrm{P}<.05)$ and $13.28(\mathrm{P}<.01)$.

\section{Results and Discussion}

Parameter estimates from Models 1 and 2 for the 12 populations are given in Table 2. Except for Charolais and Hereford, estimates of direct heritability $\left(h^{2}\right)$ were similar in the populations, ranging from .22 to .34. For all but two populations (Charolais and Simmental), estimates of maternal heritabilities $\left(\mathrm{m}^{2}\right)$ were smaller than $h^{2}$; the smallest estimates of $\mathrm{m}^{2}$ were for the composites and for breeds with a dualpurpose background (Braunvieh, Gelbvieh, Pinzgauer, and Red Poll). For these breeds, estimates of the correlations between direct and maternal genetic effects $\left(r_{a m}\right)$ were positive, but they were negative for traditional British beef breeds (e.g., Angus, Hereford). Direct and maternal genetic covariances were estimated previously from these data (Bennett and Gregory, 1996; Van Vleck et al., 1996), although different models were used.

When Model 2 was applied, estimates of variance components due to grandmaternal genetic effects could be obtained for 7 of the 12 populations. For the other five populations, the grandmaternal genetic variance tended to become negative during iteration and, therefore, was set to a very small positive value $\left(10^{-8}\right)$ in order to keep the matrix of the genetic (co)variances positive definite while the corresponding covariances were set to zero. Setting variance components to zero or near-zero when they become negative is only one way to deal with this problem. There are approaches for Newton methods (see, e.g., Harville, 1977; J ohnson and Thompson, 1995; Meyer and Smith, 1996) that keep the estimates in the parameter space or that, after reparameterization, do not yield negative estimates. When all grandmaternal components were set to near zero, Models 1 and 2 were identical for Pinzgauer, Simmental, MARC I, and MARC III. Only for three populations could 
estimates of all the (co)variance components fitted in Model 2 be obtained.

Estimates of $h^{2}$ from Model 2 were only slightly different from those with Model 1 . There was a tendency for higher estimates of $\mathrm{m}^{2}$ with Model 2 than with Model 1 . However, an increase in the estimates of $\mathrm{m}^{2}$ from Model 1 to Model 2 comparable in magnitude to the increase observed for selected lines of Hereford cattle (Dodenhoff et al., 1998a) occurred only for Charolais. Including grandmaternal effects in the model had little effect on estimates of $\mathrm{m}^{2}$ for Angus and Gelbvieh. In analyses of larger data sets of Angus cattle, estimates of $\mathrm{m}^{2}$ increased on average from .15 with Model 1 to .21 with Model 2 (Dodenhoff et al., 1998b). Estimates of grandmaternal genetic effects $\left(\mathrm{g}^{2}\right)$ were small and similar across populations (.03 to .06). Estimates of $g^{2}$ had to be set to near zero for those populations that had the smallest estimates of $\mathrm{m}^{2}$ with Model 1 (Pinzgauer, MARC I, MARC III).
For Hereford and Simmental, estimates of $\mathrm{g}^{2}$ had to be set to near zero, even though, for these breeds, estimates of $\mathrm{m}^{2}$ with Model 1 were relatively large. In those cases the data structure may have been insufficient to estimate all parameters in a model with a relatively complicated covariance structure such as Model 2.

Changes in estimates of the correlation between direct and maternal genetic effects seemed to be closely related to changes in estimates of $\mathrm{m}^{2}$, indicating that increased estimates of maternal genetic variances were more important for the increased estimates of $r_{a m}$ from Model 2 than increased estimates of direct-maternal genetic covariances. For Charolais and Limousin, the correlation was positive with Model 2 but was negative with Model 1. Large negative correlations were observed between maternal and grandmaternal genetic effects $\left(r_{\mathrm{mg}}\right)$, thus confirming Willham (1972), who expected the covariance

Table 2. Estimates of parameters ${ }^{\mathrm{a}}$ and standard errors (in parentheses) for weaning weight $(\mathrm{kg})$ by breed and model

\begin{tabular}{|c|c|c|c|c|c|c|c|c|c|c|c|c|c|c|c|c|c|}
\hline \multirow[b]{2}{*}{ Population } & \multicolumn{6}{|c|}{ Model 1} & \multicolumn{11}{|c|}{ Model 2} \\
\hline & $\mathrm{h}^{2}$ & $\mathrm{~m}^{2}$ & $r_{a m}$ & $p^{2}$ & $e^{2}$ & $\sigma_{\mathrm{p}}^{2}$ & $2 \log \mathrm{L}$ & $h^{2}$ & $\mathrm{~m}^{2}$ & $g^{2}$ & $r_{a m}$ & $r_{a g}$ & $r_{\mathrm{mg}}$ & $p^{2}$ & $q^{2}$ & $e^{2}$ & $\sigma_{\mathrm{p}}^{2}$ \\
\hline Angus & $\begin{array}{c}.25 \\
(.07)\end{array}$ & $\begin{array}{c}.11 \\
(.06)\end{array}$ & $\begin{array}{l}-.15 \\
(.22)\end{array}$ & $\begin{array}{c}.21 \\
(.04)\end{array}$ & $\begin{array}{c}.46 \\
(.05)\end{array}$ & 430 & $15.2^{c}$ & $\begin{array}{c}.22 \\
(.06)\end{array}$ & $\begin{array}{c}.11 \\
(.07)\end{array}$ & $\begin{array}{c}.06 \\
(.00)\end{array}$ & $\begin{array}{l}-.14 \\
(.22)\end{array}$ & $\begin{array}{c}.64 \\
(.30)\end{array}$ & $\begin{array}{l}-.85 \\
(.42)\end{array}$ & $\begin{array}{c}.15 \\
(.06)\end{array}$ & $\begin{array}{c}.02 \\
(.04)\end{array}$ & $\begin{array}{c}.46 \\
(.05)\end{array}$ & 441 \\
\hline Braunvieh & $\begin{array}{c}.27 \\
(.08)\end{array}$ & $\begin{array}{c}.09 \\
(.05)\end{array}$ & $\begin{array}{c}.28 \\
(.31)\end{array}$ & $\begin{array}{l}.11 \\
(.04)\end{array}$ & $\begin{array}{c}.49 \\
(.06)\end{array}$ & 489 & 3.7 & $\begin{array}{c}.30 \\
(.08)\end{array}$ & $\begin{array}{c}.17 \\
(.09)\end{array}$ & $\begin{array}{c}.04 \\
(.05)\end{array}$ & $\begin{array}{c}.38 \\
(.24)\end{array}$ & $\begin{array}{l}-.70 \\
(.44)\end{array}$ & $\begin{array}{l}-.53 \\
(.40)\end{array}$ & $\begin{array}{c}.03 \\
(.07)\end{array}$ & $\begin{array}{c}.01 \\
(.04)\end{array}$ & $\begin{array}{c}.49 \\
(.06)\end{array}$ & 482 \\
\hline Charolais & $\begin{array}{c}.11 \\
(.05)\end{array}$ & $\begin{array}{c}.14 \\
(.06)\end{array}$ & $\begin{array}{l}-.12 \\
(.30)\end{array}$ & $\begin{array}{c}.21 \\
(.05)\end{array}$ & $\begin{array}{c}.56 \\
(.05)\end{array}$ & 646 & $10.7^{b}$ & $\begin{array}{c}.11 \\
(.05)\end{array}$ & $\begin{array}{c}.32 \\
(.14)\end{array}$ & $\begin{array}{c}.06 \\
(.00)\end{array}$ & $\begin{array}{c}.07 \\
(.26)\end{array}$ & $\begin{array}{l}-.48 \\
(.44)\end{array}$ & $\begin{array}{l}-.91 \\
(.36)\end{array}$ & $\begin{array}{c}.09 \\
(.08)\end{array}$ & $-^{d}$ & $\begin{array}{c}.56 \\
(.05)\end{array}$ & 639 \\
\hline Gelbvieh & $\begin{array}{c}.27 \\
(.09)\end{array}$ & $\begin{array}{c}.10 \\
(.06)\end{array}$ & $\begin{array}{c}.05 \\
(.31)\end{array}$ & $\begin{array}{c}.01 \\
(.04)\end{array}$ & $\begin{array}{c}.61 \\
(.07)\end{array}$ & 609 & 5.6 & $\begin{array}{c}.26 \\
(.08)\end{array}$ & $\begin{array}{c}.11 \\
(.05)\end{array}$ & $\begin{array}{c}.05 \\
(.00)\end{array}$ & $\begin{array}{l}-.01 \\
(.30)\end{array}$ & $\begin{array}{c}.57 \\
(.38)\end{array}$ & $\begin{array}{l}-.83 \\
(.42)\end{array}$ & $-^{d}$ & $-^{d}$ & $\begin{array}{c}.59 \\
(.07)\end{array}$ & 626 \\
\hline Hereford & $\begin{array}{c}.17 \\
(.07)\end{array}$ & $\begin{array}{c}.16 \\
(.08)\end{array}$ & $\begin{array}{l}-.37 \\
(.26)\end{array}$ & $\begin{array}{c}.29 \\
(.06)\end{array}$ & $\begin{array}{c}.44 \\
(.05)\end{array}$ & 518 & .06 & $\begin{array}{c}.17 \\
(.07)\end{array}$ & $\begin{array}{c}.16 \\
(.08)\end{array}$ & $-^{d}$ & $\begin{array}{l}-.36 \\
(.26)\end{array}$ & $-^{d}$ & $-^{d}$ & $\begin{array}{c}.25 \\
(.07)\end{array}$ & $\begin{array}{c}.04 \\
(.05)\end{array}$ & $\begin{array}{c}.44 \\
(.05)\end{array}$ & 515 \\
\hline Limousin & $\begin{array}{c}.26 \\
(.08)\end{array}$ & $\begin{array}{c}.14 \\
(.07)\end{array}$ & $\begin{array}{l}-.18 \\
(.25)\end{array}$ & $\begin{array}{c}.18 \\
(.05)\end{array}$ & $\begin{array}{c}.45 \\
(.06)\end{array}$ & 526 & 4.0 & $\begin{array}{c}.25 \\
(.08)\end{array}$ & $\begin{array}{c}.22 \\
(.11)\end{array}$ & $\begin{array}{c}.03 \\
(.00)\end{array}$ & $\begin{array}{c}.01 \\
(.24)\end{array}$ & $\begin{array}{l}-.03 \\
(.59)\end{array}$ & $\begin{array}{l}-.99 \\
(.55)\end{array}$ & $\begin{array}{l}.10 \\
(.07)\end{array}$ & $\begin{array}{c}.02 \\
(.04)\end{array}$ & $\begin{array}{c}.45 \\
(.06)\end{array}$ & 529 \\
\hline Pinzgauer & $\begin{array}{c}.34 \\
(.10)\end{array}$ & $\begin{array}{c}.04 \\
(.05)\end{array}$ & $\begin{array}{c}.40 \\
(.57)\end{array}$ & $\begin{array}{c}.11 \\
(.05)\end{array}$ & $\begin{array}{c}.47 \\
(.08)\end{array}$ & 539 & $.00^{\mathrm{e}}$ & $\begin{array}{c}.34 \\
(.10)\end{array}$ & $\begin{array}{c}.04 \\
(.05)\end{array}$ & $-^{d}$ & $\begin{array}{c}.40 \\
(.57)\end{array}$ & $-^{d}$ & $-^{d}$ & $\begin{array}{c}.11 \\
(.05)\end{array}$ & $-^{d}$ & $\begin{array}{c}.47 \\
(.08)\end{array}$ & 539 \\
\hline Red Poll & $\begin{array}{c}.25 \\
(.07)\end{array}$ & $\begin{array}{c}.07 \\
(.05)\end{array}$ & $\begin{array}{c}.64 \\
(.37)\end{array}$ & $\begin{array}{c}.11 \\
(.04)\end{array}$ & $\begin{array}{c}.49 \\
(.06)\end{array}$ & 436 & 1.7 & $\begin{array}{c}.26 \\
(.08)\end{array}$ & $\begin{array}{c}.10 \\
(.07)\end{array}$ & $\begin{array}{c}.05 \\
(.05)\end{array}$ & $\begin{array}{c}.64 \\
(.31)\end{array}$ & $\begin{array}{l}-.33 \\
(.40)\end{array}$ & $\begin{array}{l}-.44 \\
(.43)\end{array}$ & $\begin{array}{c}.07 \\
(.06)\end{array}$ & $-^{d}$ & $\begin{array}{c}.49 \\
(.06)\end{array}$ & 431 \\
\hline Simmental & $\begin{array}{c}.22 \\
(.07)\end{array}$ & $\begin{array}{c}.25 \\
(.07)\end{array}$ & $\begin{array}{l}-.10 \\
(.21)\end{array}$ & $\begin{array}{c}.05 \\
(.04)\end{array}$ & $\begin{array}{c}.51 \\
(.06)\end{array}$ & 517 & $.00^{\mathrm{e}}$ & $\begin{array}{c}.22 \\
(.07)\end{array}$ & $\begin{array}{c}.25 \\
(.07)\end{array}$ & $-^{d}$ & $\begin{array}{l}-.10 \\
(.21)\end{array}$ & $-^{d}$ & $-^{d}$ & $\begin{array}{c}.05 \\
(.04)\end{array}$ & $-^{d}$ & $\begin{array}{c}.51 \\
(.06)\end{array}$ & 517 \\
\hline MARC I & $\begin{array}{c}.34 \\
(.06)\end{array}$ & $\begin{array}{c}.03 \\
(.02)\end{array}$ & $\begin{array}{c}.51 \\
(.41)\end{array}$ & $\begin{array}{c}.11 \\
(.03)\end{array}$ & $\begin{array}{c}.47 \\
(.05)\end{array}$ & 557 & $.00^{\mathrm{e}}$ & $\begin{array}{c}.34 \\
(.06)\end{array}$ & $\begin{array}{c}.03 \\
(.02)\end{array}$ & $-^{d}$ & $\begin{array}{c}.51 \\
(.41)\end{array}$ & $-^{d}$ & $-^{d}$ & $\begin{array}{c}.11 \\
(.03)\end{array}$ & $-^{d}$ & $\begin{array}{c}.47 \\
(.05)\end{array}$ & 557 \\
\hline MARC II & $\begin{array}{c}.23 \\
(.05)\end{array}$ & $\begin{array}{c}.08 \\
(.03)\end{array}$ & $\begin{array}{c}.08 \\
(.22)\end{array}$ & $\begin{array}{c}.11 \\
(.02)\end{array}$ & $\begin{array}{c}.57 \\
(.04)\end{array}$ & 563 & 5.5 & $\begin{array}{c}.25 \\
(.05)\end{array}$ & $\begin{array}{c}.14 \\
(.05)\end{array}$ & $\begin{array}{c}.04 \\
(.02)\end{array}$ & $\begin{array}{c}.31 \\
(.19)\end{array}$ & $\begin{array}{l}-.65 \\
(.28)\end{array}$ & $\begin{array}{l}-.65 \\
(.26)\end{array}$ & $\begin{array}{c}.05 \\
(.04)\end{array}$ & $-^{d}$ & $\begin{array}{c}.57 \\
(.04)\end{array}$ & 556 \\
\hline MARC III & $\begin{array}{c}.33 \\
(.06)\end{array}$ & $\begin{array}{c}.03 \\
(.03)\end{array}$ & $\begin{array}{c}.37 \\
(.40)\end{array}$ & $\begin{array}{l}.16 \\
(.03)\end{array}$ & $\begin{array}{c}.45 \\
(.05)\end{array}$ & 585 & $.00^{\mathrm{e}}$ & $\begin{array}{c}.33 \\
(.06)\end{array}$ & $\begin{array}{c}.03 \\
(.03)\end{array}$ & $\begin{array}{l}-^{d} \\
\end{array}$ & $\begin{array}{c}.37 \\
(.40)\end{array}$ & $\begin{array}{l}-^{d} \\
-\end{array}$ & $\begin{array}{l}-^{d} \\
\end{array}$ & $\begin{array}{c}.16 \\
(.03)\end{array}$ & $\begin{array}{l}-^{d} \\
\end{array}$ & $\begin{array}{c}.45 \\
(.05)\end{array}$ & 585 \\
\hline
\end{tabular}

$\mathrm{a}^{2}=$ direct heritability, $\mathrm{m}^{2}=$ maternal heritability, $\mathrm{g}^{2}=$ grandmaternal heritability, $\mathrm{r}_{\mathrm{am}}=$ genetic correlation between direct and maternal effects, $r_{a g}=$ genetic correlation between direct and grandmaternal effects, $r_{m g}=$ genetic correlation between maternal and grandmaternal effects, $p^{2}=$ fraction of variance due to maternal permanent environmental effects, $q^{2}=$ fraction of variance due to grandmaternal permanent environmental effects, $\mathrm{e}^{2}=$ fraction of variance due to temporary environmental effects, $\sigma_{\mathrm{p}}^{2}=$ phenotypic variance, 2 logL $=2 \mathrm{log}$ likelihood as deviation from Model 1.

${ }^{\mathrm{b}}$ Function value smaller $(\mathrm{P}<.05)$ than the function value for Model 1 .

${ }^{C}$ Function value smaller $(P<.01)$ than the function value for Model 1 .

dEstimate set to zero.

eModel 1 and 2 identical after grandmaternal components set to zero. 
between these effects to be negative if overfeeding a calf has a negative influence on its performance as a dam. This negative influence seemed to be smaller for breeds that had a moderate positive correlation between direct and maternal genetic effects (Braunvieh, Red Poll, and MARC II). The large negative estimates of $r_{m g}$ may be the reason for the increase in estimates of $\mathrm{m}^{2}$ from Model 1 to Model 2. A dam with above-average maternal ability most likely will have had a dam that also had above-average maternal ability and, therefore, has had a negative influence on the daughter's maternal ability, and vice versa. Model 2 accounts for these effects, and, in Model 1, maternal effects are "overshadowed" by grandmaternal effects. Estimates of the correlations between direct and grandmaternal genetic effects $\left(r_{\text {ag }}\right)$ ranged from -.70 to .64 , with the sign being the opposite of the sign for the estimates of $r_{a m}$. Any relationship of the magnitude of the $r_{a g}$ estimates to any of the other parameters was not obvious. When Willham (1972) defined a model to include grandmaternal effects he questioned the existence of a non-zero covariance between direct and grandmaternal genetic effects.

Estimates of the fraction of variance due to permanent maternal environmental effects $\left(p^{2}\right)$ decreased from Model 1 to Model 2. Only for three of the populations in which grandmaternal genetic effects were found could estimates of the fraction of variance due to permanent grandmaternal environmental effects $\left(q^{2}\right)$ be obtained. Those estimates were small (.01 to .02), suggesting that permanent environmental effects of the granddam probably could be dropped from the model without greatly affecting the results. These effects then would likely be included in the permanent environmental effects of the dam (Willham, 1972).

Likelihood ratio tests suggested that grandmaternal heritabilities of at least .06 were required to make Model 2 a significantly better fit to the data than Model 1 (Table 2).

Standard errors of the estimated parameters from Model 2, particularly of the correlations, were large (Table 2), indicating that much larger data sets will be necessary in order to obtain standard errors of a reasonable magnitude from models with complicated (co)variance structures.

Product-moment and rank correlations between breeding values for direct weaning weight and be tween breeding values for maternal weaning weight from Models 1 and 2 are given in Table 3. Including grandmaternal effects in the model had a greater effect on breeding values for maternal weaning weight than on breeding values for direct weaning weight. For Angus, the correlations between breeding values for maternal weaning weight were considerably lower than those for the other breeds. The magnitude of the estimated grandmaternal genetic effects and the
Table 3. Product-moment (PM) and rank (R) correlations between estimated breeding values for direct weaning weight (WWd) from Models 1 and 2 and between estimated breeding values for maternal

weaning weight (WWm) from Models 1 and 2

for breeds with nonzero estimates of grandmaternal genetic variance

\begin{tabular}{llllll}
\hline \hline & \multicolumn{2}{c}{$W W d$} & & \multicolumn{2}{c}{$W W m$} \\
\cline { 2 - 3 } \cline { 5 - 6 } Breed & PM & $\mathrm{R}$ & & $\mathrm{PM}$ & $\mathrm{R}$ \\
\hline Angus & .977 & .977 & & .821 & .792 \\
Braunvieh & .990 & .989 & & .982 & .981 \\
Charolais & .985 & .978 & & .948 & .940 \\
Gelbvieh & .987 & .987 & & .937 & .935 \\
Limousin & .993 & .992 & & .951 & .946 \\
Red Poll & .997 & .997 & & .990 & .992 \\
MARC II & .992 & .990 & & .960 & .958 \\
\hline
\end{tabular}

difference between the likelihood values from Models 1 and 2 , respectively, seemed to have a greater effect on the correlations than an increase in the estimates of the maternal genetic effects from Model 1 to Model 2.

More recently, other approaches have dealt with the problem of a potentially biased correlation between direct and maternal effects (e.g., Robinson, 1996b; Koerhuis and Thompson, 1997; Lee and Pollak, 1997). Koerhuis and Thompson (1997) considered the problem to be the assumption that an environmental dam-offspring covariance does not exist. They obtained the best results from a model that did not allow for a dam-offspring covariance but did include the dam's phenotype as a linear covariate (Falconer, 1965). A model that includes grandmaternal effects, such as the one used in this analysis, is computationally more demanding than the integrated "Falconer-Willham" model (Koerhuis and Thompson, 1997) because it fits a third random genetic effect that directly considers the genetic effect of a dam on her daughter's maternal ability. However, the integrated "Falconer-Willham" model overcomes criticism by Lande and Kirkpatrick (1990), who argued that Willham's (1963, 1972) models do not account for cycles of maternal effects. Quintanilla et al. (1998) proposed a model that includes a covariance between permanent maternal environmental effects of all dams in line of descent to account for a nongenetic covariance between direct and maternal effects.

Similar to Robinson (1996b), Lee and Pollak (1997) focused on the effect of sire $\times$ year interactions on the correlation between direct and maternal effects and found the correlation to be biased downward if sire $\times$ year interactions are ignored in the estimation model. Meyer (1997), who applied the "FalconerWillham" model and additionally included a sire $x$ herd-year interaction, found direct-maternal genetic correlations to be considerably less negative compared to the "usual" model. 


\section{Implications}

Including grandmaternal effects in models for genetic analysis of weaning weight seems to be important for populations with large maternal effects. Results show that grandmaternal effects exist in some populations. Probably more importantly, when grandmaternal effects exist, maternal heritabilities may be underestimated and correlations between direct and maternal effects may be biased downward with models typically used to estimate maternal effects for weaning weight. Because of the relatively large standard errors in the present analyses, larger data sets need to be analyzed in order to estimate the magnitude of biases in different populations more conclusively.

\section{Literature Cited}

Baker, R. L. 1980. The role of maternal effects on the efficiency of selection in beef cattle: A review. In: Proc. N.Z. Soc. Anim. Prod. 40:285-303.

Bennett, G. L., and K. E. Gregory. 1996. Genetic (co)variances among birth weight, 200-day weight, and postweaning gain in composites and parental breeds of beef cattle. J . Anim. Sci. 74: 2598-2611.

BIF. 1996. Guidelines for Uniform Beef Improvement Programs (7th Ed.). Beef Improvement Federation, Colby, KS.

Cantet, R.J .C., D. D. Kress, D. C. Anderson, D. E. Doornbos, P. J . Burfening, and R. L. Blackwell. 1988. Direct and maternal variances and covariances and maternal phenotypic effects on preweaning growth of beef cattle. J. Anim. Sci. 66:648-660.

Dobson, A. J . 1990. An Introduction to Generalized Linear Models. Chapman and Hall, New York.

Dodenhoff, J., L. D. Van Vleck, S. D. Kachman, and R. M. Koch. 1998a. Parameter estimates for direct, maternal, and grandmaternal genetic effects for birth weight and weaning weight in Hereford cattle. J. Anim. Sci. 76:2521-2527.

Dodenhoff, J ., L. D. Van Vleck, and D. E. Wilson. 1998b. Comparison of models to estimate maternal genetic effects for weaning weight. J. Anim. Sci. 76 (Suppl. 1):52 (Abstr.).

Falconer, D. S. 1965. Maternal effects and selection response. In: Genetics Today. Proc. XI Int. Congr. Genet. Vol 3. p 763. The Hague, The Netherlands.

Gregory, K. E., L. V. Cundiff, and R. M. Koch. 1991. Breed effects and heterosis in advanced generations of composite populations for growth traits in both sexes of beef cattle. J. Anim. Sci. 69: 3202-3212.

Harville, D. A. 1977. Maximum likelihood approaches to variance component estimation and related problems. J. Am. Stat. Assoc. 72:320-338.

J ohnson, D. L., and R. Thompson. 1995. Restricted maximum likelihood estimation of variance components for univariate animal models using sparse matrix techniques and average information. J. Dairy Sci. 78:449-456.

Koch, R. M. 1972. The role of maternal effects in animal breeding: VI. Maternal effects in beef cattle. J . Anim. Sci. 35:1316-1323.

Koerhuis, A.N.M., and R. Thompson. 1997. Models to estimate maternal effects for juvenile body weight in broiler chickens. Genet. Sel. Evol. 29:225-249.

Lande, R., and M. Kirkpatrick. 1990. Selection response in traits with maternal inheritance. Genet. Res. 55:189-197.

Lee, C., and E. J . Pollak. 1997. Relationship between sire $\times$ year interactions and direct-maternal genetic correlation for weaning weight of Simmental cattle. J. Anim. Sci. 75:68-75.

Meyer, K. 1992a. Bias and sampling covariances of estimates of variance components due to maternal effects. Genet. Sel. Evol. 24:487-509.

Meyer, K. 1992b. Variance components due to direct and maternal effects for growth traits of Australian beef cattle. Livest. Prod. Sci. 31:179-203.

Meyer, K. 1997. Estimates of genetic parameters for weaning weight of beef cattle accounting for direct-maternal environmental covariances. Livest. Prod. Sci. 52:187-199.

Meyer, K., and S. P. Smith. 1996. Restricted maximum likelihood estimation for animal models using derivatives of the likelihood. Genet. Sel. Evol. 28:23-49.

Perez-Enciso, M., I. Misztal, and M. A. Elzo. 1992. FSPAK-An interface for public domain sparse matrix subroutines. Proc. 5th World Congr. Genet. Appl. Livest. Prod. 22:77-78.

Quintanilla, R., L. Varona, M. R. Pujol, and J. Piedrafita. 1998. Maternal animal model with correlation between maternal permanent environmental effects in beef breeding. Proc. 6th World Congr. Genet. Appl. Livest. Prod. 23:259-262.

Robinson, D. L. 1996a. Estimation and interpretation of direct and maternal genetic parameters for the weights of Australian Angus cattle. Livest. Prod. Sci. 45:1-11.

Robinson, D. L. 1996b. Models which might explain negative correlations between direct and maternal genetic effects. Livest. Prod. Sci. 45:111-122.

Stuart, A., and J. K. Ord. 1994. Kendall's Advanced Theory of Statistics. Volume 1: Distribution Theory (6th Ed.). Halsted Press, New York.

Takahashi, K., J. Fagan, and M. S. Chin. 1973. Formation of a sparse bus impedance matrix and its application to short circuit study. In: Proc. 8th Inst. PICA Conf. p 63. Minneapolis, MN.

Thompson, R. 1976. The estimation of maternal genetic variances. Biometrics 32:903-917.

Van Vleck, L. D., K. E. Gregory, and G. L. Bennett. 1996. Direct and maternal genetic covariances by age of dam for weaning weight. J . Anim. Sci. 74:1801-1805.

Waldron, D. F., C. A. Morris, R. L. Baker, and D. L. J ohnson. 1993. Maternal effects for growth traits in beef cattle. Livest. Prod. Sci. 34:57-69.

Willham, R. L. 1963. The covariance between relatives for characters composed of components contributed by related individuals. Biometrics 19:18-27.

Willham, R. L. 1972. The role of maternal effects in animal breeding: III. Biometrical aspects of maternal effects in animals. J . Anim. Sci. 35:1288-1293. 